\title{
CAPÍTULO 12 \\ FORMAÇÃO CONTINUADA DE PROFESSORES PARA A \\ EDUCAÇÃO INCLUSIVA: PELA SUPERAÇÃO DO \\ PRAGMATISMO REFLEXIVO - CONTRIBUIÇÕES DA PERSPECTIVA HISTÓRICO-CULTURAL*
}

\author{
Eliane Candida Pereira \\ Maria Eliza Mattosinho Bernardes
}

\section{Introdução}

A discussão e a análise acerca da formação de professores para a educação inclusiva, propostas nesse texto, emergem da necessidade de compreensão das condições formativas mediadoras da organização de práticas pelo professor, no contexto da Política Nacional de Educação Especial na perspectiva da educação inclusiva (BRASIL, 2008) e das políticas nacionais de formação continuada.

No movimento histórico de transformação das políticas de direito das pessoas com deficiência, Transtorno do Espectro Autista e altas habilidades, foi assegurada a possibilidade de matrícula em classes regulares com $\mathrm{O}$ atendimento educacional especializado ofertado de maneira complementar (BRASIL, 2008). Nessa política educacional, assim como em outras políticas vigentes, indica-se a formação dos professores como uma das ações para a sua implementação.

A Lei de Diretrizes e Bases da Educação Nacional (LDBEN) de 1996 determinou que os sistemas de ensino devem assegurar aos profissionais da educação "[...] período reservado a estudos, planejamento e avaliação, incluído na carga de Trabalho" (BRASIL, 1996, p. 23). Ao longo dos anos foram constituídos referenciais e indicativos nacionais para Formação de Professores que abordaram tanto os aspectos da formação inicial quanto da formação continuada assegurada na legislação.

No primeiro Referencial publicado após a LDBEN foram apresentadas críticas aos modelos vividos nas formações continuadas, apontando que "[...] quase sempre se dá uma ênfase muito grande à transmissão de informação teórica: não existe uma cultura de análise da prática pedagógica dos professores no trabalho de formação” (BRASIL, 1999, p. 47). Indica-se nesse documento a oferta de "atualizações, aprofundamento das temáticas educacionais", com apoio na "[...] reflexão sobre a prática educativa, promovendo um processo constante de autoavaliação que oriente a construção contínua de competências profissionais" (BRASIL, 1999, p. 70, grifo nosso).

Anos depois, resultante de debates vinculados ao Plano Nacional de Educação 2014-2024 (BRASIL, 2014) e à definição das Diretrizes Curriculares Nacionais para a formação de professores, o MEC publica a Resolução CNE/CP 02/2015 (BRASIL, 2015, p. 5, grifo nosso), que indica como principais finalidades da formação continuada "a reflexão sobre a prática educacional e a busca de aperfeiçoamento técnico, pedagógico, ético e político do profissional docente".

O estudo aqui apresentado evidencia a problematização sobre a conceituação de prática e sobre a reflexão sobre a prática que está presente nas formulações das políticas para a formação de professores, geralmente destacada pelos profissionais como princípio para a constituição da formação continuada, bem como sobre o conhecimento teórico necessário para a transformação das ações para uma educação inclusiva.

${ }^{*}$ DOI - 10.29388/978-65-86678-97-0-f.173-188 
O objetivo do presente texto é sintetizar a análise realizada em uma pesquisa acadêmica desenvolvida entre 2016 e 2020¹ que tornou evidente quanto é necessário investir para que, no processo de formação continuada, as próprias funções psicológicas superiores dos professores sejam movimentadas, visto que isso incide diretamente sobre o trabalho educativo que desenvolvem - no caso, com alunos público-alvo da Educação Especial na perspectiva da educação inclusiva. A pesquisa teve por objetivo analisar a relação entre desenvolvimento de formação continuada e a reorganização do ensino pelos professores participantes, acarretando as aprendizagens dos seus alunos.

O referencial teórico metodológico adotado na pesquisa fundamenta-se no Materialismo Histórico-Dialético pela concepção de homem e mundo, de ciência e o propósito de explicar a realidade buscando possibilidades para sua transformação, realizando-se um conjunto de ações para investigações teóricas e pesquisa de campo. Assim, no decurso deste texto, são apresentados os fundamentos teórico-metodológicos da atividade formativa e das condições necessárias para a superação do pragmatismo reflexivo. $\mathrm{O}$ movimento e os procedimentos metodológicos para a execução da pesquisa de campo deuse com a objetivação da atividade formativa com um curso de aperfeiçoamento para professores da educação básica desenvolvido na Universidade de São Paulo por pesquisadores do Grupo de Estudo e Pesquisa Educação, Sociedade e Políticas Públicas: Concepções da Teoria Histórico-Cultural (GEPESPP).

A análise do movimento da realidade na formação docente leva-nos a defender a tese de que a reelaboração de práticas pelos professores da educação básica em processos formativos continuados, com o intuito de ensinar a todos os estudantes, está relacionada ao movimento de constituição do pensamento teórico em tais práticas e a sua objetivação, superando o pragmatismo presente na "reflexão sobre a prática" e aproximando-se da práxis que transforma as ações e os sujeitos do processo. (PEREIRA, 2021). Identifica-se como síntese desse processo, como unidade complexa, a atividade formativa que integra conhecimentos teórico-práticos.

\section{A atividade formativa: práxis na formação e na atuação de professores}

Vygotski, Luria e Leontiev explicitaram os fundamentos dos processos de formação e desenvolvimento das funções psicológicas superiores no enfoque histórico cultural. Nos estudos sobre o desenvolvimento histórico do homem primitivo e da criança, Vygotski e Luria (1996, p. 51) afirmam que existem "[...] três linhas principais de desenvolvimento do comportamento - evolutiva, histórica e ontogenética [...]". Trata-se da base explicativa dos aspectos biopsíquicos historicamente instituídos como unidade na constituição e no desenvolvimento cultural do sujeito humano a partir da formação da espécie humana e dos processos evolutivos, nas dimensões filogenética e da ontogenética.

Leontiev (1978), em estudos sobre a formação e desenvolvimento humano, dá ênfase à análise de atividades humanas gerais, como o trabalbo e a comunicação, e às atividades específicas oriundas da vida em sociedade. Sistematiza a Teoria da Atividade, entendida como unidade molar nos estudos sobre a dimensão dialética dos processos de transformação da natureza e da própria subjetividade humana, a partir da condição ativa dos sujeitos visando uma determinada finalidade. De acordo com o autor, ao estar em atividade o sujeito humano cria e externaliza a cultura de forma material e não-material ao longo da sua existência. Trata-se de um movimento constante de internalização e externalização, permanência e criação da cultura. Os processos de comunicação nas

${ }^{1}$ A pesquisa, realizada por Eliane Candida Pereira e orientada pela Profa. Dra. Maria Eliza Mattosinho Bernardes, foi desenvolvida no Programa de Pós-Graduação em Educação stricto-sensu para o nível de doutorado, na Faculdade de Educação da Universidade de São Paulo. 
relações sociais possibilitam movimentos interpsíquicos e intrapsíquicos na mediação da cultura e criam possibilidades para a humanização dos sujeitos (VIGOTSKI, 2000). Entende-se, portanto que, enquanto atividade geral humana, no enfoque histórico-cultural, a educação é considerada essencial para o processo de humanização e se objetiva em diferentes condições concretas e a partir de finalidades específicas.

Leontiev (1983) sistematizou a estrutura das atividades humanas e explicou que há inter-relações entre necessidades, motivos, ações e operações, objeto e objetivos da atividade na prática social global. Afirma que, uma atividade se caracteriza pela relação entre motivos e necessidades básicas constituídas historicamente, sendo, então, realizada por ações, que, por sua vez, estão atreladas aos seus respectivos objetivos. As formas de realização das ações, uma vez que automatizadas, são chamadas por Leontiev (1983) de operações e estão relacionadas às condições concretas para a realização da atividade. Considerando a unidade entre tais elementos, o autor explica que a atividade não pode ser tomada como sinônimo de ação, tampouco pode ser considerada isolada das condições concretas de existência que emergem da particularidade do contexto histórico e cultural em que ocorrem. Com avanços das discussões teórico-metodológicas fundamentadas nos pressupostos do Materialismo Histórico-Dialético, estreitam-se as inter-relações entre os conceitos de atividade e de práxis. Sánchez Vázquez (2011, p. 398), tecendo análises mediadas por estudos marxistas, define que práxis é "a atividade material humana transformadora do mundo e do próprio homem". Assim, conforme aponta, toda práxis é uma atividade, mas nem toda atividade é uma práxis. De acordo com o autor, a atividade enquanto práxis,

[...] implica na intervenção da consciência, graças à qual o resultado existe duas vezes - e em tempos diferentes -: como resultado ideal e como produto real. $\mathrm{O}$ resultado ideal, que se pretende obter, existe primeiro idealmente, como mero produto da consciência, e os diversos atos do processo se articulam ou estruturam de acordo com o resultado que se dá primeiro no tempo, isto é, o resultado ideal. Em virtude dessa antecipação do resultado que se deseja obter, a atividade propriamente humana tem um caráter consciente. (SÁNCHEZ VÁZQUEZ, 2011, p. 187). (SIC)

Considera-se a relevância do caráter consciente na prática social visando a sua dupla objetivação, assim como salienta-se a inter-relação entre as atividades que se conceituam como educativa, pedagógica e formativa. De acordo com Bernardes (2011, p. 331), "[...] a condição de existência dos sujeitos como ser social determina o modo de organização das ações na atividade educativa". Concebe-se, neste sentido, que a educação enquanto atividade geral humana, objetivada duplamente nos diversos processos educativos, possibilitam aos sujeitos a produção da cultura e a apropriação da condição humana de existência, constituída histórica e culturalmente.

A atividade pedagógica, no entanto, é objetivada nos processos educativos sistematizados de forma intencional no contexto escolar (BERNARDES, 2009). A atividade pedagógica objetiva-se duplamente, seja na dimensão da transformação e desenvolvimento das funções psíquicas superiores ao se apropriarem do conhecimento teórico e científico, seja na organização do ensino que sistematiza os modos de ação de ensino e de estudo. De acordo com Bernardes (2011, p. 330)

[...] a mediação das significações na atividade pedagógica ocorre intencionalmente quando inseridas num contexto cujos objetivos de ensino e de estudo correspondam ao fim desejado, à sua finalidade, ou seja, quando as ações do educador e dos educandos visam ao processo de humanização pela apropriação da produção cultural humana. 
A atividade formativa é entendida como uma especificidade da atividade pedagógica sendo objetivada no contexto da formação de profissionais que atuam na educação, em todos os níveis de escolarização, e em diferentes espaços formativos (ASSALI, 2014, PEREIRA, 2016). Assali (2014) ao analisar processos formativos de professores na educação formal constatou que:

Para a atividade formativa se objetivar na prática social entende-se ser essencial que ocorra a correspondência entre os elementos constitutivos da atividade dos sujeitos na formação continuada, cuja finalidade, objeto, ações e operações estejam fundidas no motivo, aos quais estão relacionados com o objetivo da própria atividade. Ressalta-se que este processo não ocorre de forma natural e espontânea, mas deve ser organizado na particularidade dos espaços formativos. (ASSALI, 2014, p. 130)

Assim, problematizam-se os propósitos de formação de professores para a educação inclusiva desconectados da sua própria finalidade, o desenvolvimento de ações e operações do professor em atividade de ensino e dos estudantes em atividade estudo, assim como para o desenvolvimento psíquico do próprio professor e de seus alunos. É com essa premissa que defendemos a necessidade de superação do conceito de professor reflexivo na formação continuada de professores, apresentando-se a seguir a análise do conceito a partir da compreensão da sua gênese.

\section{O pragmatismo reflexivo na educação no Brasil}

Saviani (1999) aponta que, a partir da ascensão da burguesia, passou a ser defendido o direito de todos à educação juntamente com os ideários da democracia. A escola supostamente diminuiria as desigualdades sociais pela aquisição do conhecimento. No entanto, na realidade, nem todos tinham acesso a ela ou não aprendiam de fato, levando-se à discussão sobre a necessidade de alteração do modelo pedagógico.

As defesas sobre modelos pedagógicos instituídas no Brasil relacionam-se, em alguma medida, ao movimento denominado Escola Nova, que se estabeleceu como uma crítica à chamada Escola Tradicional e, em relação à formação continuada dos professores, vinculam-se aos pressupostos de desenvolvimento do professor reflexivo (DUARTE, 2003).

Selma Garrido Pimenta (2012) analisou como os propósitos de desenvolvimento do professor reflexivo foram disseminados a partir das produções do norte-americano Donald Schön, o qual, alicerçado em estudos de filosofia, especialmente sobre as elaborações de John Dewey, propõe que a formação dos profissionais da educação escolar valorize a experiência em si e a reflexão na experiência, assim como no conceito de conhecimento tácito para se referir ao conhecimento na ação.

Dewey (2007) adotava o pragmatismo como método filosófico para superar o dualismo empírico, em uma tentativa de unificar razão e experiência, teoria e prática, a fundamentando-se nas produções de Charles Sanders Peirce e de William James. O autor explica que o desenvolvimento do pragmatismo por Peirce, por sua vez, se deu por influência de Kant, que buscava uma síntese entre racionalismo e empirismo. Segundo ele, inicialmente, Peirce era um empirista, mas entendia que seu sistema não poderia ser tratado como "praticalismo", como considerado por alguns de sua época, buscando, então, a referência terminológica do pragmatismo em Kant e, com essas premissas, propôs uma filosofia que valorizasse a experiência.

A partir desses pressupostos, Dewey discute a pedagogia pautada na postura ativa do sujeito vinculada ao pensamento reflexivo. Ele define que o pensamento é "a representação mental de algo não realmente presente, e pensar consiste na sucessão de tais 
representações" (DEWEY, 1979, p. 15) e que o pensamento reflexivo é a melhor "forma de pensar". Segundo o autor, "o pensamento reflexivo faz um ativo, prolongado e cuidadoso exame de toda crença ou espécie hipotética de conhecimento, exame efetuado à luz dos argumentos que a apoiam e das conclusões a que chega" (DEWEY, 1979, p. 18).

Sob esses constructos, Dewey defende a necessidade de um método para comprovação das ideias, que envolve necessariamente hipóteses, coleta de exemplos, observações, comparações, experimentações, relações de conceitos e comprovação do conceito. Entende que dessa forma não estaria fazendo a defesa da empiria, mas de um método analítico, supostamente enfatizando o valor da abstração.

No âmbito da formação continuada, Pimenta (2012) aponta que as ideias de Donald Schön acerca da reflexão sobre a prática foram rapidamente apropriadas em diferentes países no contexto de reformas curriculares e de questionamentos sobre formação de professores. A autora identifica críticas ao modelo que foram desenvolvidas em diferentes países, apontando um possível reducionismo e os limites dessas propostas por desconsiderar a realidade social em que ocorrem as ações, bem como a insuficiência da reflexão individual sobre as práticas. No entanto, essas críticas tiveram menor reverberação na discussão sobre o tema no Brasil.

No campo das políticas públicas educacionais no território nacional, observa-se que a Resolução CNE/CP 02/2015 (BRASIL, 2015, p. 5) mantém a reflexão sobre a prática e o aperfeiçoamento técnico como finalidades que antecedem as demais na formação docente. Nota-se, assim, a tendência à permanência da dimensão técnica ao se defender a prática como eixo central dos processos formativos em detrimento de seus fundamentos e dos conteúdos a ela vinculados nas políticas vigentes, conforme assinala Martins (2010) acerca de diretrizes anteriores. Concebe-se, portanto, que os pressupostos teóricos para as propostas de reflexão sobre a prática enraízam-se no arcabouço teórico do pragmatismo, que busca responder aos problemas práticos imediatos e de maneira individual.

Como possibilidade de compreensão da realidade e de sua transformação, incorporando os ideais de superação da suposta fragmentação entre teoria e prática, mas movimentando o pensamento caracteristicamente indutivo ou hipotético dedutivo com o pensamento de caráter dialético, encontram-se os pressupostos do Materialismo Histórico e Dialético postulados por Marx e Engels, que retomam o conceito de práxis visando a superação do pragmatismo reflexivo. A superação do pragmatismo reflexivo pela atividade formativa

Hamada (2017), ao realizar estudos sobre a palavra práxis, identifica que o termo foi usado por Aristóteles nas discussões sobre a teoria da ação, na busca por uma relação entre teoria e prática na ciência do conhecimento e considerando-o como uma finalidade permanente para o aperfeiçoamento humano. Posteriormente, novas perspectivas filosóficas retomam o termo, tais como as discussões realizadas por Rousseau, Kant, Hegel e Feuerbach. No confronto das concepções vigentes em sua época, Marx elabora um conceito de práxis, visando superar as lacunas presentes nas discussões idealistas de Hegel e no materialismo de Feuerbach, visto que ambos utilizavam explicações parciais e fragmentadas sobre a realidade. Para o materialismo, o movimento do real ocorre de forma exterior ao homem, enquanto para o idealismo tudo se origina na ideia e no pensamento humano. A nova concepção materialista elaborada por Marx, a partir da crítica às duas correntes filosóficas vigentes em seu tempo, situa a práxis como o ato que possibilita a unidade entre esses dois movimentos indissociáveis: 
[...] na práxis existem dois momentos inseparáveis: da ideação de um resultado ao nível da consciência que vai orientar a ação e da efetivação do resultado real. Decorre, assim, a transformação de uma situação, na qual tanto o sujeito que age quanto a realidade ou o objeto que sofre a ação não são mais os mesmos. (HAMADA, 2017, p. 88)

Nessa complexa relação instituída, a prática determina a teoria porque é a sua fonte, real e objetiva, e por desencadear as suas finalidades. Ao mesmo tempo, a teoria não se submete tão somente à prática, restringindo-se a reproduzi-la em descrições e explicações, mas pode se antecipar a ela.

Sánchez Vázquez (2011) explicita que há a consciência prática, que conduz as ações em si, e a consciência da práxis, que permite saber sobre a própria práxis.

O mesmo autor analisa que há uma aparente coincidência quando o pragmatismo e o materialismo dialético colocam a prática no centro da discussão sobre o conhecimento humano. Contudo as significações de prática são distintas nas duas vertentes explicativas. O pragmatismo trata de uma prática individual, uma experiência subjetiva para satisfação de necessidades e interesses imediatos. Em decorrência disso, o prático volta-se ao utilitário e o teórico ao útil (SÁNCHEZ VÁZQUEZ, 2011, p. 269). No Materialismo HistóricoDialético, a prática relaciona-se a uma ação objetiva transformadora relacionada às condições históricas e materiais. Em consequência, a prática pode revelar "[...] a verdade ou a falsidade, isto é, a correspondência ou não de um pensamento com a realidade" (SÁNCHEZ VÁZQUEZ, 2011, p. 244).

No movimento de superação do pragmatismo reflexivo também há que se considerar a relação entre sentido e significado da atividade para a constituição da práxis. Leontiev (1983) afirma que as atividades objetivadas na realidade prática material, a partir de um motivo e de uma finalidade a ser atingida na realidade, ficam carregadas das significações firmadas socialmente, que, internalizadas pelo homem, são subjetivadas. Desta forma, a relação entre sentido pessoal e significado social se constitui nas atividades humanas em geral, e nas atividades objetais, entre elas, na atividade educativa, pedagógica e formativa.

De acordo com Marx (2008), na sociedade capitalista, as ações desenvolvidas por um sujeito em seu trabalho podem perder a relação com a finalidade da atividade em si, constituindo-se como alienada. Explica que, na maioria das relações estabelecidas com o trabalho transformado em mercadoria, o ser humano vive uma situação de estranhamento sobre a sua própria produção, que é desempenhada sem relação com os motivos e com a finalidade do trabalho na constituição do gênero humano. Portanto, o trabalho, como atividade em que o conjunto dos homens transformam a natureza e se transformam, assumiu características peculiares no modo de produção capitalista e, a partir dessa peculiaridade, outras dimensões sociais constituíram seus desdobramentos, entre essas, a educação escolar, impactando nas possibilidades de emancipação humana. Tonet (2017, p. 6) sistematiza a contradição anunciada ao afirmar que:

Emancipação humana, no sentido marxiano do termo, é uma forma de sociabilidade na qual todos os indivíduos serão plenamente livres, isto é, uma forma de sociedade em que os homens serão, efetiva e o mais plenamente possível, senhores da sua história. [...]. Porém, para que os homens sejam efetivamente livres, faz-se necessária uma base material que lhes propicie o acesso aos bens - materiais e espirituais - necessários à satisfação das suas necessidades e, com isso, à sua plena realização como membros do gênero humano.

A educação escolar seria uma das condições necessárias para a apropriação da cultura elaborada historicamente, mas, contraditoriamente, na particularidade da sua 
constituição, permeada pelas relações de exploração e lutas de classe, entende-se que essa objetivação se inviabiliza, constitui-se de modo alienado ao sujeito. Desta forma, faz-se necessária a recuperação da finalidade da educação escolar e o sentido do trabalho dos professores, atuando no campo da formação da consciência do professor enquanto pertencente à classe trabalhadora.

Sob essa perspectiva, Bernardes (2012b), ao discutir as mediações simbólicas na atividade pedagógica, também defende que uma das possibilidades de superação da alienação, ainda que parcial, ocorre pelo processo de apropriação do conhecimento como produção histórica do gênero humano, movimento esse que se mostra fragilizado na organização social em que nos inserimos. Trata-se, portanto, de recuperar o significado da atividade pedagógica como mediadora do desenvolvimento humano e possibilitar o desenvolvimento do referido sentido para os professores e os estudantes.

Com base em tais constructos teóricos apresentados, assume-se que o movimento transformador de um processo formativo a ser promovido para atender às demandas advindas da realidade da Educação Especial na perspectiva da educação inclusiva não se trata de reflexão sobre a prática, mas da constituição da práxis pelo professor. Sob essa perspectiva, Bernardes (2012b, p. 79) reitera:

\begin{abstract}
Tem-se como premissa que as mediações simbólicas na atividade pedagógica somente são instituídas na organização do ensino como práxis em nossa sociedade quando as condições e circunstâncias próprias da formação do professor criam possibilidades para que tenha consciência de sua função social numa sociedade de classes e, ao mesmo tempo, que compreenda os limites reais do ensino quando a organização social, política e econômica não prioriza, nos processos educacionais, a promoção do homem como elemento universal da condição humana.
\end{abstract}

Constata-se, no entanto, que os limites da reflexão sobre a prática como finalidade na formação de professores no Brasil não abarcam a necessidade de superação do pragmatismo reflexivo, não transformam a realidade nem criam possibilidades para a emancipação humana.

No caso específico da Política Nacional de Educação Especial na perspectiva da educação inclusiva, questiona-se: por que incluir a todos nas situações de ensino em classes regulares? Que concepção de desenvolvimento e de aprendizagem sustentam as práticas pedagógicas assim instituídas? Quais as finalidades da educação escolar para formação da humanidade em cada ser humano?

Foi nas tramas desse contexto teórico-filosófico que é definido o problema desta pesquisa: quais condições teórico-práticas necessárias na formação continuada de professores para a educação inclusiva criam possibilidades para a superação do pragmatismo reflexivo visando à práxis transformadora? Para a objetivação da pesquisa de campo, foi oferecido o curso gratuito de extensão universitária denominado Educação inclusiva e desafios cotidianos para ensinar: contribuições da teoria histórico-cultural na Universidade de São Paulo, no ano de 2018, a professores atuantes na educação básica e que tivessem, na época, alunos em processo de inclusão.

\title{
O movimento da pesquisa de campo e a constituição de uma atividade formativa.
}

Com o objetivo de criar uma coletividade de estudo para problematizar as práticas pedagógicas de professores para ensinar a todos os estudantes a partir de um movimento teórico-prático fundamentado no enfoque histórico-cultural, o curso de extensão universitária contou com a participação de seis professores da educação básica, 
identificadas na pesquisa como professores participantes. O curso foi organizado por sete pesquisadoras integrantes do GEPESPP USP que se colocaram em atividade visando a objetivação da atividade formativa. Estas pesquisadoras são identificadas na pesquisa como professoras ministrantes.

A pesquisa de campo objetivou-se na prática social nas seguintes etapas: Ipreparação do curso com planejamento, aprovações institucionais necessárias e seleção dos participantes; II - execução do curso com encontros presenciais - estudos prévios de textos pelos participantes e realização de tarefas relacionadas ao planejamento e registro das práticas em suas respectivas turmas havendo alunos com deficiências ou com necessidades de intervenções diferenciadas no mesmo contexto educativo que os demais; IIIacompanhamento ao longo do curso com devolutivas individuais sobre as tarefas realizadas, bem como discussões no coletivo; IV-acompanhamento após-curso, com aplicação de questionário sobre condições vividas pelos professores participantes e consulta a registros das práticas no ano posterior.

Entre os meses de fevereiro e junho de 2018 ocorreram com os professores participantes encontros presenciais semanais, encontros mensais de agosto a novembro do mesmo ano e um contato por e-mail em junho de 2019. Os encontros presenciais foram gravados e transcritos, assim como somaram-se à compilação dos dados os registros escritos produzidos pelos professores durante o curso e após o mesmo, sobre as aulas que organizaram em suas respectivas turmas, bem como suas respostas a um questionário.

A apresentação e a discussão dos dados ocorreram a partir da análise de episódios (MOURA,2004), análise da enunciação verbal (BERNARDES, 2019) e da elaboração de um modelo teórico (DAVIDOV, 1988) do movimento de transformação observado em duas professoras participantes que responderam ao contato seis meses após o término do último encontro presencial.

A organização das ações e operações na atividade formativa em análise se objetivou por meio de: a) estudos prévios de textos que propiciam a significação das práticas em andamento em suas respectivas turmas por novas elaborações teóricas para o ensino de todos os estudantes, b) reflexões dialógicas intencionalmente organizadas por meio de situações desencadeadoras nos encontros presenciais, c) explicações teórico-práticas, d) sínteses conceituais escritas, e) devolutivas das produções orais e escritas dos professores participantes, f) relatos orais da experiência dos professores participantes, g) organização de tarefas de estudo que favorecessem a intervenção verbal entre os pares, h) elaborações escritas sobre as ações dos professores participantes na prática pedagógica com seus alunos.

Para evidenciar o processo de transformação da prática pedagógica, a seguir é apresentado um episódio sobre o movimento dialógico do conceito e uma sintese da transformação na prática docente de uma das professoras participantes do curso de formação continuada - a professora C.

- O movimento dialógico do conceito na atividade formativa

Para exemplificar o movimento conceitual na atividade formativa destaca-se que, em uma das aulas, estabeleceu-se como objetivo específico evidenciar a compreensão dos professores participantes sobre os conceitos que medeiam explicações sobre o desenvolvimento bumano, lidos em referenciais teóricos indicados previamente e discutidos nas aulas anteriores, entre eles: desenvolvimento cultural, atividade, função psicológica superior, zona de desenvolvimento próximo e processo de compensação.

A partir das questões desencadeadoras: (1) "Na perspectiva histórico-cultural, há uma crítica à biologização na compreensão do desenvolvimento bumano. Que crítica é essa e, a partir dela, que concep̧̧ão de desenvolvimento bumano a Teoria Histórico-Cultural pode nos traz̧er como contribuição? "; 
(2) "A partir da Psicologia Histórico-Cultural, trabalha-se com as funções psicológicas superiores. O que são elas e como se constituem?", solicitou-se para que os professores participantes se organizassem em subgrupos e que elaborassem um esquema como resposta às perguntas.

A ação teve caráter de controle da aprendizagem pelos próprios professores participantes e pelas professoras ministrantes (BERNARDES,2021a) e, ao mesmo tempo, caracterizou-se como uma ação formativa, na medida em que a elaboração de um esquema explicativo em grupo permitiu que as apropriações conceituais fossem reelaboradas, buscando-se a superação dos conceitos espontâneos (DAVIDOV, 1988). $\mathrm{Na}$ análise das enunciações estabelecidas constata-se um movimento inicial no coletivo dos professores participantes sem necessariamente chegar-se a uma síntese, como se observa no grupo semântico A:

\section{Grupo Semântico A - Identificação de conceitos envolvidos na concepção de desenvolvimento humano na Teoria Histórico-Cultural}

(1) E: Cada grupo vai contar para os demais o processo até chegar no esquema que elaborou, explicando os destaques que resolveu fazer para responder à questão.

(2) L: Eu e a C [subgrupo 1] bolamos esse esquema para responder à pergunta 1. Como se fosse um pequeno mapa. A gente critica inicialmente a teoria inatista, a biologização, como a gente viu no nosso primeiro texto "Criança não é manga". A gente partiu dessa ideia. A gente critica essa teoria. Então o fator principal que alterou para a gente foi a ideia de humanização. A partir dela, a gente foi citando outros fatores: a cultura, o meio, as relações, a teoria histórico-cultural, desenvolvimento, aprendizagem, ensino.

(3) E: Mas o que é a humanização, que vocês colocaram aí no meio do esquema?

(4) L: Essa humanização é a crítica, a teoria de que os fatores biológicos não são determinantes. A partir do movimento histórico-cultural, você pode desenvolver a teoria da criança ultrapassar esse fator biológico limitante através do meio cultural, do ambiente.

(5) C: Não desconsidera outras teorias, mas acrescenta e supera através do processo, pela teoria histórico-cultural. Então, o homem vai se humanizar a partir da cultura, do meio e das relações. Não é só o biológico. Esse processo de humanização também é aprendido e através do ensino ele vai sendo transmitido para as próximas gerações. Aí, cada vez esse trabalho vai se tornando mais complexo. E a partir da aprendizagem a gente desenvolve as funções superiores.

O mesmo se constata nas enunciações dos professores participantes do subgrupo que produziu o segundo esquema apresentado:

(6) Ma: A gente [subgrupo 2] fez um esquema do funcionamento psicológico-social, para responder à pergunta 2, começando pelo indivíduo. Nascemos e depois vamos sendo construídos através das relações sociais, o meio social. Tem as funções elementares, que nascemos com elas, as sensações. Depois, nós vamos construindo a linguagem, memória, sentimento, pensamento e outras funções.

(7) A: A gente fez várias setinhas. Aqui é o indivíduo e suas funções elementares... (Depois que fizemos percebemos que esquecemos de fazer setinhas vai e volta...) Ele vai se construindo através das funções elementares, das psicológicas, das relações sociais, do meio, da cultura em que ele vive, que são complexas. A gente colocou algumas só para ilustrar, mas para dizer que é através disso, dessas relações que vão e que voltam, do meio, da cultura, no final, está tudo interligado. 
Figura: Esquemas produzidos em grupos pelos professores participantes para responder questões sobre o desenvolvimento humano na perspectiva da psicologia histórico-cultural.
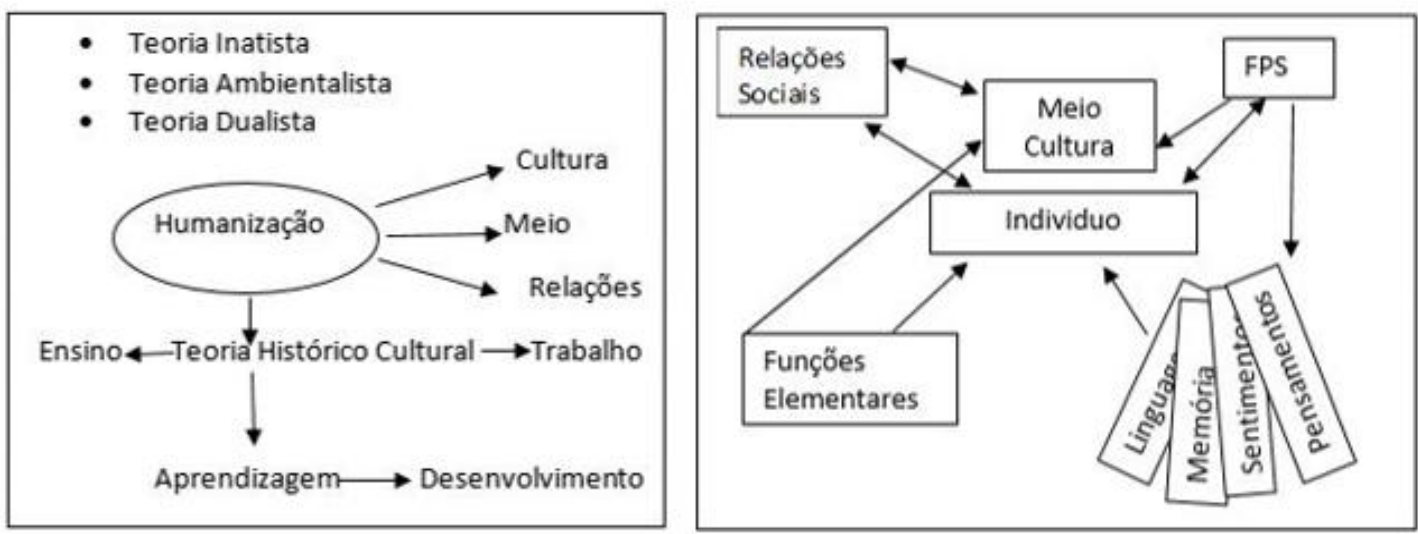

Fonte: Elaboração a partir de arquivos do curso de atualização Educação Inclusiva e Desafios Cotidianos para Ensinar - Contribuições da Teoria Histórico-Cultural.

Os indícios do movimento conceitual ocorrem a partir de intervenções da professora ministrante que podem ser consideradas manifestações de alterações nas elaborações conceituais pelos professores participantes, destacando-as em negrito fragmentos semânticos quando, a partir das mediações dialógicas, ocorreram explicações dos professores participantes sobre os esquemas elaborados.

\section{Grupo Semântico B - Estabelecimento de nexos conceituais}

(1) ME: Então pega o inverso. O que na resposta delas complementa a resposta deles? Abre o cartaz e coloca na frente. Como que a resposta deles complementa a delas e a delas complementa a deles? Qual é a conexão entre esses dois esquemas?

(2) L: Sim, tudo está interligado em ambos.

(3) ME: Qual a palavra-chave que interliga esses dois esquemas?

(4) Ma: Humanização?

(5) ME: Humanização. Agora, por quê? O que representa a humanização que tem no esquema de vocês?

(6) Ma: Que nós nascemos e vamos nos humanizando através de todas essas relações, de todos esses sentimentos.

(7) ME: Muito bem, mas o que está expresso no seu esquema que trata especificamente desse processo de humanização? Onde é que está isso no seu esqueminha?

(8) Ma: Linguagem, memória, sentimentos, pensamentos.

(9) ME: O que são funções elementares mesmo?

(10) Ma: Sensações.

(11) ME: É tudo o que os animais têm...

(12) A: A gente até estava discutindo a questão de que só o humano pode ter, né?

(13) ME: As funções elementares todos têm. Todos os seres vivos não vegetais... Qual a relação disso com o processo de humanização? Como ele dá esse salto de qualidade quando a gente chama de humanização? Se dá quando essas funções elementares fazem o quê?

(14) Ma: As funções psicológicas...

(15) Docente ME: Se transformam em funções superiores. Certo? Essa superação das funções elementares em funções superiores é o que vai significar, objetivar o processo de humanização. Bacana isso que vocês fizeram. Muito bacana. 
O movimento dialógico do conceito (BERNARDES, 2021a) foi utilizado como recurso pedagógico na atividade formativa no processo de apropriação conceitual (DAVIDOV, 1988) dos referenciais teóricos estudados previamente pelos professores participantes e para a reflexão dos registros e análises das práticas instituídas em suas respectivas turmas. Assim, o sistema de ações e operações na atividade formativa, promoveu transformações na apropriação das significações teórico-práticas pelos professores participantes da pesquisa.

- $\quad$ Sintese da transformação na prática docente - a professora participante $C$

Ao longo do período entre os meses de fevereiro a maio de 2018 observou-se, nas análises de enunciações verbais em aula registradas por vídeo, que a professora participante C. adotou o movimento de experimentação das "sugestões" de ações didáticas propiciadas nas aulas do curso; com dificuldades em dissertar sobre suas próprias práticas, sem expor com clareza sobre o que era necessário desenvolver de fato com a sua aluna cega, ainda que valorizando resultados obtidos. Notou-se a tendência de C. utilizar de perguntas para confirmar suas compreensões, suscitando apenas indícios de apropriação conceitual objetivada na sua própria prática pedagógica. Exemplo deste modo de ação é verificado quando a participante elabora questões diretas, tais como "o que seriam as técnicas físicas e psicológicas de compensação?” (Transcrição do encontro em 23/4/2018); ou manifestações tais como "é nas relações que ocorre a aprendizagem, não é? E através dela é que ocorre o desenvolvimento, é isso?" (Transcrição do encontro em 7/5/2018); "que outros encaminhamentos você acha serem necessários a partir da resposta dela, quais as possibilidades na zona de desenvolvimento próximo? Eu estou confusa em como seguir. (Transcrição do encontro em 12/6/2018).

Se consideradas as fases do pensamento reflexivo analisadas por Dewey, a participante estaria em desenvolvimento da reflexão, visto que demonstrava “ (1) um estado de dúvida, hesitação, perplexidade, dificuldade mental, o qual origina o ato de pensar; e (2) um ato de pesquisa, procura, inquirição, para encontrar material que resolva a dúvida, assente e esclareça a perplexidade" (DEWEY, 1979, p. 22).

No entanto, para que o pensamento cotidiano pudesse ser superado, $\mathbf{C}$ demandava colocar-se em movimento analítico. Conforme as explicações de Davidov (1988, p. 150, tradução nossa):

[...] o pensamento teórico é realizado de duas formas fundamentais: 1) com base na análise dos dados factuais e sua generalização, separa-se a abstração substancial, que fixa a essência do objeto concreto estudado e se expressa em conceito de sua "célula"; 2) então, por meio da revelação das contradições nesta "célula" e da determinação do procedimento para sua solução prática, segue-se a ascensão da essência abstrata e da relação universal não desmembrada à unidade dos diversos aspectos do todo em desenvolvimento, para o concreto.

No processo de superação de pensamentos cotidianos, segundo o autor, a análise e a generalização compõem movimentos integrados do pensamento e buscam identificar os aspectos que compõem a questão internamente, como se inter-relacionam, assim como estão relacionados à totalidade. Ao se identificar aspectos inter-relacionados, necessariamente, encontram-se também suas contradições, permitindo elaborações sobre sua gênese e novas possibilidades de objetivação.

Com vistas a tais movimentos, as devolutivas das produções escritas dos professores participantes buscaram direcionar a reelaboração analítica das práticas, assim como intentaram problematizar a coerência entre objetivo - ações e operações - finalidades dos professores participantes em atividade de ensino. Analogamente ao que C. organizava para que a sua aluna aprendesse, que pudesse ampliar e expressar melhor seus pensamentos 
por meio da linguagem oral e escrita, percebeu-se a mesma necessidade no movimento formativo da própria professora participante $\mathbf{C}$.

Os registros orais e escritos evidenciam sinais do movimento analítico professora participante $\mathbf{C}$ à medida que novos conceitos foram apropriados, tais como a constituição da linguagem e do pensamento na perspectiva da Teoria Histórico-Cultural, a periodização a afetividade no desenvolvimento humano, levando-a a considerar novas possibilidades nas suas práticas, sustentadas por novas formas de apresentá-las, como se observa em seu registro produzido em junho de 2018. Ainda que as aproximações analíticas tenham ocorrido parcialmente no registro feito por ela em junho, novos patamares da (3) significação de práticas inclusivas foram alcançados. Evidencia-se, portanto, que os conceitos teóricos passam a ser instrumentos mediadores para operar, tanto com a organização, quanto na análise das próprias práticas.

Seis meses após os encontros presenciais em 2018, em junho de 2019 os professores participantes que entregaram a tarefa final do curso foram contatados por $e$ mail para que respondessem a um questionário e compartilhassem planos e registros de suas ações de ensino em andamento. No questionário a professora participante C identificou como principal impacto, em sua prática em andamento em 2019, o conhecimento do conceito de periodização do desenvolvimento e as possibilidades relacionadas à necessidade da "comunicação íntima e pessoal". Segundo ela, tais conceitos favoreceram que analisasse as possibilidades relacionadas à aproximação da inserção dos estudantes do Ensino Médio em atividades profissionais, pensando, então, nas ações necessárias para a sua aluna cega no último ano desse nível de ensino.

Ao continuar responsável pela mesma aluna em 2019, no último ano do Ensino Médio, conforme registros escritos compartilhados por e-mail, o foco de ensino estabelecido pela professora participante foi organizar situações em que todos os alunos pudessem vivenciar situações relacionadas a uma transição em seu desenvolvimento: a inserção na preparação para o trabalho formal. Foi possível observar, pelos planos e registros enviados, que a professora participante C. manteve interface com os demais professores em um projeto que proporcionou situações informativas e vivências aos alunos sobre a cegueira. Entre as ações, ocorreram palestras e oficinas relacionadas às situações inclusivas em ambiente de trabalho, e a aluna cega conduziu uma oficina sobre como os cegos podem ler por meio do braille.

Tal situação parece revelar uma nova forma de organização do ensino por parte da professora participante C. a partir da compreensão das possibilidades da aluna cega estabelecidas pelas relações de ajuda na ação pedagógica. Ao mesmo tempo, os planos de ensino e registros sobre a prática não revelaram com clareza que as situações comunicativas organizadas pela professora participante C. e envolviam o conhecimento de gêneros de discurso a serem ensinados, identificado como um certo limite na (re)organização do ensino.

\section{A atividade formativa como práxis transformada e transformadora}

Constata-se, a partir da pesquisa de campo no curso de formação continuada, que as ações formativas organizadas pelos professores ministrantes do curso também são colocadas em movimento de transformação. Ao organizarem e reorganizarem as ações formativas, os professores ministrantes também são transformados quando, coletivamente, estudam e promovem reflexões críticas sobre a própria prática. Tal fato ocorre, pois, a formação em curso visa promover ações formativas adequadas, de tal forma que possam, de fato, operar com abstrações teórico-explicativas sobre as suas escolhas didáticas. Ao mesmo tempo, os professores participantes em formação, dialeticamente, também transformam suas práticas pedagógicas, visando a organização e reorganização de ações pedagógicas adequadas para a aprendizagem e o desenvolvimento de seus alunos. 
Compreende-se, portanto, que os processos de apropriação conceitual decorrentes de ações formativa e pedagógica adequadas à aprendizagem e desenvolvimento de seus alunos, conforme afirma Vygotski (1994), é essencial para analisar as manifestações conceituais de professores e estudantes em atividade, demonstrando domínio de suas condutas e realizando ações coletivas que sejam correspondentes aos objetivos e finalidades das atividades às quais se integram.

Reforça-se a premissa de que os sujeitos em atividade (re)criam as atividades sociais pela participação coletiva e que é no processo de objetivação da prática social que "[...] essa atividade se converte em individual e os meios de sua organização, em internos" (DAVIDOV, 1988, p. 11). Ao mesmo tempo, permite reiterar que a objetivação do pensamento constituído nas atividades formativa e pedagógica se dá no âmbito da prática; no caso dos professores ministrantes, no efetivo exercício da práxis formativa; no caso dos professores participantes, a objetivação ocorre na atividade pedagógica. Trata-se de considerar o incessante movimento dialético entre os sujeitos em atividade formativa e pedagógica, configurado não como etapas ou níveis em que se encontrariam os professores ministrantes e participantes, mas trata-se de um movimento de transformação contínuo que caracteriza a formação humana pela práxis transformadora.

No campo da atividade formativa, o sistema de ações instituído para a educação inclusiva demandou uma análise constante de suas relações com a finalidade da objetivação da atividade pedagógica pelos professores participantes como práxis transformadora. $\mathrm{O}$ esquema a seguir expressa o sistema de ações e operações na atividade formativa enquanto práxis transformadora:

Figura 1: Representação do movimento vivido na análise dos dados sobre a atividade formativa para a educação inclusiva

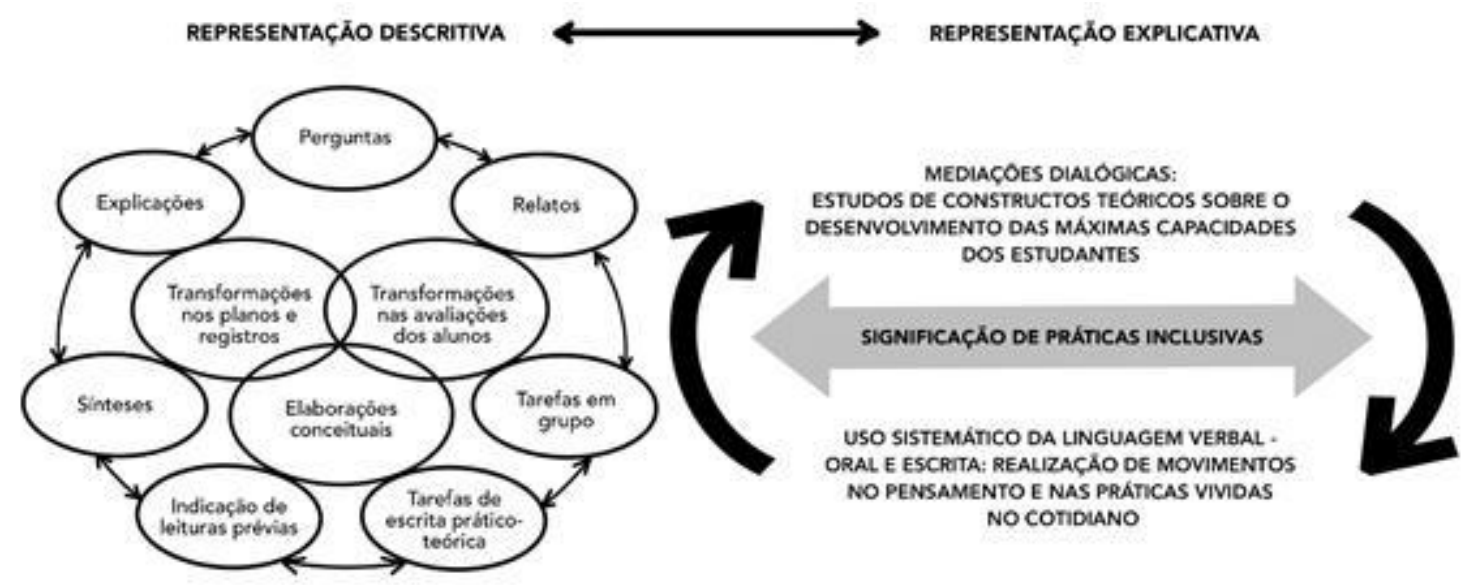

Fonte: PEREIRA, 2021. p.135

Os dados corroboram com pesquisas anteriores (BERNARDES, 2012a; PEREIRA, 2016) que analisaram transformações em práticas pedagógicas engendradas em processos de significação da finalidade da atividade de ensino e de estudo, alicerçadas na concepção de educação escolar como instrumento mediador do processo de desenvolvimento humano e na compreensão da função da constituição da linguagem. Reitera-se que tais ações precisam necessariamente articular dialeticamente a organização do ensino, o conhecimento teórico e a constituição de uma coletividade de estudo.

Reconhecendo-se os limites e possibilidades das ações e operações na atividade formativa, é possível defender que, para a reelaboração de práticas pelos professores de educação básica participantes em processos formativos, visando ensinar a todos os estudantes, há que se instaurar o movimento de constituição do pensamento teórico nas 
práticas e a sua objetivação, superando o pragmatismo reflexivo e aproximando-se da práxis que transforma as ações e os sujeitos do processo. A síntese desse processo objetiva-se na atividade formativa que integra, como unidade complexa, conhecimentos teórico-práticos.

\section{Considerações finais}

Diante da proposta de sintetizar as questões oriundas da pesquisa acadêmica sobre a formação continuada de professores com alunos em processo de inclusão e a (re)organização do ensino pelos professores participantes, promovendo aprendizagens dos seus alunos que movimentem seus desenvolvimentos, há de se problematizar as reflexões teórico-práticas anunciadas sobre a atividade formativa e a questão das políticas públicas sobre formação de professores pautadas na perspectiva do professor reflexivo.

Ressalta-se que tais reflexões evidenciam que a superação da reflexão sobre a prática pelos professores requer transformações radicais na consciência dos professores atuantes na educação escolar e na organização do ensino e da aprendizagem fundamentada na concepção dialética e histórica de formação e desenvolvimento do sujeito humano e no modo como o mesmo atua na prática social global. Para tanto, concebe-se a necessidade de criar condições concretas adequadas na formação continuada de professores que tenham como finalidade a apropriação da complexidade da humanidade, visando o desenvolvimento dos sujeitos e da sociedade.

Uma das condições necessárias é a objetivação de mediações dialógicas na atividade formativa para a educação inclusiva operadas com conceitos sobre o desenvolvimento humano em suas máximas possibilidades, considerando o desenvolvimento das funções psicológicas superiores também na educação escolar.

O desenvolvimento das funções psicológicas superiores, como explicado nos estudos vigotskianos, inter-relaciona o domínio de elementos da cultura, de processos mentais e do próprio comportamento, desde a sensação, percepção, atenção, memória, à linguagem, ao pensamento, às emoções e aos sentimentos. Assim, objetiva-se no sujeito o desenvolvimento histórico da humanidade. Ao mesmo tempo, são as funções psicológicas superiores que permitem operar com informações sobre a realidade e modificá-la.

Ao participarem das situações formativas com mediações dialógicas voltadas à significar o ensino com a perspectiva da aprendizagem para o desenvolvimento humano de todos os estudantes, identificando as suas implicações educacionais, os professores podem operar transformações na atividade pedagógica e, nesse movimento, também se transformarem com o desenvolvimento do seu pensamento conceitual sobre a realidade, da sua capacidade de síntese, de planejamento e de avaliação, movimentando as próprias funções psicológicas superiores. Portanto, tais constructos-possibilitam superações no pensamento teórico e nas práticas de ensino, de forma sistemática e intencional, realizada no coletivo de profissionais que integram a atividade formativa, enquanto práxis transformadora.

Outra questão refere-se à organização das ações e operações de ensino e de aprendizagem que crie condições favoráveis à apropriação conceitual e promova intervenções na zona de desenvolvimento próximo dos profissionais em formação, de modo a suscitar transformações que conduzam à superação das práticas instituídas de forma consciente e que se objetive na práxis transformadora.

Tal movimento poderia ser confundido com propósitos de reflexão sobre a prática fundamentados no pragmatismo, no entanto, diferenciam radicalmente ao almejar a manifestação pela linguagem verbal de pensamentos caracteristicamente conceituais, superando a manifestação cotidiana dos pensamentos espontâneo e por complexo e, sobretudo, por manter o pensamento no processo de objetivação da práxis. Tem-se, portanto, o propósito o desenvolvimento de funções psíquicas superiores dos professores e 
de seus alunos, constituindo-se uma atividade formativa enquanto práxis transformadora $e$ transformada.

Entretanto, todas as condições vinculam-se ao contexto das políticas de formação de professores constituídas nas estruturas de uma sociedade capitalista, em que a alienação do trabalho prevalece. Trata-se de um desafio na formação de professores, tanto inicial quanto continuada, uma vez que a necessidade de superação do que está instituído na realidade alienada e alienante requer consciência das necessidades para a transformação da prática social global, posicionamento político e organização de ações coletivas na classe de trabalhadores da educação. Desvelar caminhos para tanto é a nossa necessidade enquanto formadores de educadores que possam transformar a realidade.

\section{Referências}

ASSALI, S. A.S. A formação continuada de professores: um estudo sobre as condições concretas da jornada especial integral de formação. 2014. Dissertação (Mestrado em Educação) - Universidade de São Paulo, São Paulo, 2014.

BERNARDES, M. E.M. Ensino e aprendizagem como unidade dialética na atividade pedagógica. Psicol. Esc. Educ., Campinas, v. 13, n. 2, p. 235-242, dez. 2009.

BERNARDES, M. E. M. Atividade educativa, pensamento e linguagem: contribuições da psicologia histórico-cultural. Revista Semestral da Associação Brasileira de Psicologia Escolar e Educacional, São Paulo. v. 15, n. 2, jul./dez. 2011, p. 323-332.

BERNARDES, M. E.M Mediações simbólicas na atividade pedagógica: contribuições da teoria histórico-cultural para o ensino e a aprendizagem. Curitiba: CRV, 2012a.

BERNARDES, M. E.M. Pedagogia e mediação pedagógica. In: LIBÂNEO, J. C.; ALVES, N. (orgs.). Temas de Pedagogia: diálogos entre didática e currículo. São Paulo: Cortez, 2012b. p. 77-97.

BERNARDES, M. E.M. Transformação do pensamento e da linguagem na aprendizagem de conceitos: por uma análise da enunciação verbal. In: BERNARDES, Maria Eliza Mattosinho (org.). Narrativas e psicologia da educação: pesquisa e formação. São Paulo: Terracota Editora, 2019. p. 105-120.

BRASIL. Lei no 9.394/1996, de 20 de dezembro de 1996. Estabelece as diretrizes e bases da educação nacional. Diário Oficial da União, Brasília, DF, 23 dez. 1996.

BRASIL. Lei no 13.005/2014, de 25 de junho de 2014. Aprova o Plano Nacional de Educação - PNE e dá outras providências. Diário Oficial da União, Brasília, DF, 26 jun. 2014.

BRASIL. Ministério da Educação. Conselho Nacional de Educação. Câmara de Educação Básica. Resolução CNE/CP $\mathbf{n}^{\circ} \mathbf{2}$ de 2015. Define as Diretrizes Curriculares Nacionais para a formação inicial em nível superior (cursos de licenciatura, cursos de formação pedagógica para graduados e cursos de segunda licenciatura) e para a formação continuada. Brasília: CNE/CP, 2001a.

BRASIL. Ministério da Educação. Secretaria da Educação Fundamental. Referenciais para Formação de Professores. Brasília: MEC/SEF, 1999.

BRASIL. Ministério da Educação. Política nacional de educação especial na perspectiva da educação inclusiva. Brasília: MEC/ SEESP, 2008.

DAVIDOV, V. V. La enseñanza escolar y el desarrollo psíquico: investigación psicológica teórica y experimental. Moscu: Progreso, 1988. 
DEWEY, J. Como pensamos: como se relaciona o pensamento reflexivo com o processo educativo, uma reexposição. São Paulo: Editora Nacional, 1979.

DEWEY, J. O desenvolvimento do pragmatismo americano. Scientiae Studia, v. 5, n. 2, p. $227-243,1^{\circ}$ jun. 2007.

DUARTE, N. Conhecimento tácito e conhecimento escolar na formação do professor (por que Donald Schön não entendeu Luria). Educ. Soc., Campinas, v. 24, n. 83, p. 601-625, ago. 2003.

HAMADA, I. A. Práxis, trabalho e educação. In: BERNARDES, Maria Eliza Mattosinho; BEATÓN, Guillermo Arias (orgs.). Trabalho, educação e lazer: contribuições do enfoque histórico-cultural. São Paulo: Escola de Artes, Ciências e Humanidades, 2017. p. 85-106.

LEONTIEV, A. N. N. Actividad, conciencia y personalidad. Ciudad de la Habana, Cuba: Editorial Pueblo y Educación, 1983.

LEONTIEV, A. N. N. O Homem e a Cultura. In: LEONTIEV, A. N. N. O desenvolvimento do psiquismo. Lisboa: Horizonte, 1978. p. 261-284.

MARTINS, L. M. O legado do século XX para a formação de professores. In: MARTINS, L. M. DUARTE, N. (orgs.). Formação de professores: limites contemporâneos e alternativas necessárias. São Paulo: Editora Unesp; São Paulo: Cultura Acadêmica, 2010. p. 13-31.

MARX, K. Manuscritos econômicos-filosóficos. São Paulo: Boitempo Editorial, 2008.

MOURA, O. de. Pesquisa colaborativa: um foco na ação formadora. In: BARBOSA, Raquel Lazzari Leite (org.). Trajetória e perspectivas da formação de educadores. São Paulo: Editora Unesp, 2004. p. 258-285.

PEREIRA, E. C. Os processos formativos do professor de alunos com Transtorno do Espectro Autista: contribuições da Teoria Histórico-Cultural. 2016. Dissertação (Mestrado em Educação) - Faculdade de Educação, Universidade de São Paulo, São Paulo, 2016.

PEREIRA, E. C. Formação continuada de professores para a educação inclusiva: Pela superação do pragmatismo reflexivo - Contribuições da perspectiva histórico-cultural. 2021. Tese (Doutorado em Educação) - Faculdade de Educação, Universidade de São Paulo, São Paulo, 2021.

PIMENTA, S. G. Professor Reflexivo: construindo uma crítica. In: PIMENTA, S. G.; GHEDIN, E. (orgs.). Professor reflexivo no Brasil: gênese e crítica de um conceito. São Paulo: Cortez, 2012. p. 20-62.

SÁNCHEZ VÁZQUEZ, A. Filosofia da Práxis. Buenos Aires: Consejo Latinoamericano de Ciencias Sociales - CLACSO: São Paulo: Expressão Popular, 2011.

SAVIANI, D. Escola e democracia: teorias da educação, curvatura da vara, onze teses sobre educação e política. Campinas, SP: Autores Associados, 1999.

TONET, I. A formação de professores e a possibilidade da emancipação humana. [on-line], 2017. Disponível em: http://ivotonet.xp3.biz/. Acesso em: 2 nov. 2019.

VYGOTSKY, L. S.; LURIA, A. R. Estudos sobre a história do comportamento: símios, homem primitivo e criança. Porto Alegre, RS: Artes Médicas, 1996.

VYGOTSKI, L. S. Obras escogidas. Tomo III. Madrid: Visor 2000.

VYGOTSKI, L. S. Obras escogidas. Tomo II. Madrid: Visor, 1994. 